\title{
Role of Ultrasound Guided Fine Needle Aspiration Cytology in Intra-abdominal lesion
}

\author{
Ranu Tiwari Mishra ${ }^{1}$, Pushpa Batham ${ }^{1}$, Rashmi Nayak ${ }^{1}$ \\ 1 Associate professor Department of Pathology, N.S.C.B Medical College, Jabalpur (M.P), India \\ Corresponding Author: Dr Rashmi Nayak, Associate Professor, \\ Department of pathology, N.S.C.B Govt. Medical College, Jabalpur (M.P) \\ Email: drrashminayak007@gmail.com \\ DOI : 10.47799/pimr.0802.18
}

\begin{abstract}
Introduction: All of the imaging techniques have advantages and disadvantage in various parts of the body. In intraabdominal lesion ultrasonography guided FNAC has advantage over computerised tomography guided FNAC because CT is very costly and not freely available. CT gives high dose of radiation and therefore should not be used in pregnant women and in small children whereas ultrasonography has no radiation effects and hence can be safely used in these cases. Mobile version of CT is not available and therefore it cannot be used in faraway places whereas ultrasonography machine is mobile. Thus, with localization by ultrasonography diagnosis of the malignancy and staging can be accomplished through FNAC.

Method: Total of 100 cases who came for FNAC of intraabdominal masseswere included in the study, irrespective of their age, sex or possible nature of mass. Ultrasound guided Fine needle aspiration was done in all.The aim of the present study was to assess the feasibility of ultrasound guided Fine needle aspiration cytology of routine procedure for detection of abdominal lesion.
\end{abstract}

Result: Total of 100 cases were studied. In the $80(80 \%)$ cases, aspirates were positive for malignancy and in $17(17 \%)$ cases were negative for malignancy. There were $3 \%$ false negative cases encountered. There were no false positive cases. Ultrasound was used for mass localization. In 80 positive cases of malignancy, 36 cases from liver, 10 from lymph node, 7 from gall bladder, 6 from stomach, 6 from ovary, 3 from urinary bladder, 1 from pancreas, I from uterus, 3 from miscellaneous sites.

Conclusion: Percutaneous fine needle aspiration cytology is reliable method of diagnosing the various pathological lesions of abdomen. Its diagnostic accuracy is further increased when performed under Radiological guidance. Of all modalities of guidance at present is the most suitable.

Keywords: intra-abdominal mass, FNAC, USG guided

Introduction

Almost all organs are accessible to Fine needle aspiration cytology (FNAC) like lymph nodes, breast lump, enlarged thyroid, salivary gland lesion and abdominal lesion. Initially Fine needle aspiration cytology was done only on superficial palpable masses but now with the advancement in diagnostic imaging procedures like ultrasound, computerised tomography and Magnetic resonance imaging, it is also possible to take samples from non-palpable small deep seated lesions in abdomen and thorax. There is definite advantage of Ultrasound guide FNAC over traditional FNAC in intra-abdominal lesion. The USG is capable of organ identification, obtaining detail images of organs, localizing lesion within them, demonstrating the relationship of surrounding structure (such as blood vessels, lymph nodes), demonstration of needle in the lesion and differentiation between solid and fluid filled cystic spaces. All of the imaging techniques have advantages and disadvantage in various parts of the body. In intra-abdominal lesion ultrasonography guided FNAC has advantage over computerised tomography guided FNAC because CT is very costly and not freely available. CT gives high dose of radiation and therefore should not be used in pregnant women and in small children whereas ultrasonography has no radiation effects and hence can be safely used in these cases. Mobile version of CT is not available and therefore it cannot be used in faraway places whereas ultrasonography machine is mobile.Thus, with localization by ultrasonography diagnosis of the malignancy and staging can be accomplished through FNAC. Various studies of fine needle aspiration of different types of abdominal lump under ultrasonography is available in literature- Proter B. et al(1981), Juul et al (1984). The aim of the present study was to assess the feasibility of ultrasound guided Fine needle aspiration cytology of routine procedure for detection of abdominal lesion.

\section{Material and Methods}

The present study was carried out in the Department of Pathology NSCB Medical College Jabalpur for a period of 2 years. Total of 100 cases who came for FNAC of intra-abdominal mass were included in the study, irrespective of their age, sex or possible nature of mass. Detail history and clinical examination of the patients was done. Routine investigations including bleeding time, clotting time and Prothrombin time were performed prior to ultrasound guided FNAC. An informed consent was taken after explaining procedure to the patient. Mass in question was imaged ultrasonographically to localize the origin and to decide whether or not to be aspirated. A 
routine screening of the rest of the abdomen was also carried out simultaneously. Once a target lesion/ mass has been carefully localized and characteristic assessed, depth of the lesion from preliminary image is measured and according to this needle of desire length was selected. Cutaneous needle entry site was selected and most direct shortest safest route was selected avoiding major vasculature structure. Skin overlying the marked site was thoroughly cleaned with antiseptic solution and spirit. Local anaesthesia and sedation was not given in any cases. The patient was first explained about the procedure and instruction was given to patient to hold the breath in inspiration during needle insertion so that needle pass into right tract. Depth of lesion was noted and a 21-23 gauge needle was attached to $10 \mathrm{cc}$ syringe. In case, if the depth was more 26 gauge Lumber Puncture Needle was used. Under the ultrasound guidance needle was gently pushed inside and once the needle was found inside the lesion the needle was moved back and fro within the lesion and in different direction under constant suction in order to detach the tissue fragment. When the aspiration had been completed pressure in the syringe was allowed to equalise before the needle was withdrawn from the lesion and the puncture site was sealed with a tincture benzoin cotton swab. Now the material in the needle was expelled onto glass slide and smear was made by opposition technique. Smears prepared so were fixed in $95 \%$ alcohol for at least $30 \mathrm{~min}$ and stained with H\&E staining.

\section{Result \& Discussion}

The present study comprises of 100 cases presented with intraabdominal lesion. This prospective study was conducted in department of Pathology and Radiodiagnosis, N.S.C.B Medical College, Jabalpur (M.P)

Table 1- Age distribution of cases

\begin{tabular}{|l|c|c|}
\hline Age Group & Number of cases & Percentage \\
\hline $0-10$ & 11 & $11 \%$ \\
\hline $11-20$ & 2 & $2 \%$ \\
\hline $21-30$ & 6 & $6 \%$ \\
\hline $31-40$ & 15 & $15 \%$ \\
\hline $41-50$ & 23 & $23 \%$ \\
\hline $51-60$ & 29 & $29 \%$ \\
\hline $61-70$ & 12 & $12 \%$ \\
\hline $71-80$ & 2 & $2 \%$ \\
\hline Total & 100 & $100 \%$ \\
\hline
\end{tabular}

Youngest patient was $1 \frac{1}{4}$ year old male child and oldest patient was 75 years old female. Maximum number of the patients werebetween $51-60$ years of age (29\%) and minimum number of the patients were between $11-20$ years age (2\%) and $71-80$ years (2\%). Sanjay Kumar Nigam et al (2014) in a study of intra-abdominal lumps by FNAC also observed maximum

\begin{tabular}{|l|c|c|c|}
\hline S.No. & Sex & Total No of cases & Percentage \\
\hline 1 & Male & 54 & $54 \%$ \\
\hline 2 & Female & 46 & $46 \%$ \\
\hline & Total & 100 & $100 \%$ \\
\hline
\end{tabular}

In the present study 54 cases were males and 46 cases were female and male to female ratio was 1.17:1. The male predominance was also observed in studies by Govind Krishna et al (1993)6; Zawar MP7 et al (2007) and Sobha Rani G et

al(2012). However studies by Shamshad et al (2006); Sidhalingareddy et al $(2011)^{9}$; Joao Nobrega et al(1994)10and Sanjay Kumar Nigam et al(2014) showed a female predominance. 


\section{Ranu Tiwari Mishra, et al}

Table 3- distribution of lesion in different organ

\begin{tabular}{|l|c|c|c|c|}
\hline Organ & Number & Male & Female & Percentage \\
\hline Liver & 42 & 28 & 14 & $42 \%$ \\
\hline Para aortic lymph node & 12 & 9 & 3 & $12 \%$ \\
\hline Ovary & 10 & - & 10 & $10 \%$ \\
\hline Gallbladder & 10 & 3 & 7 & $10 \%$ \\
\hline Stomach & 6 & 2 & 4 & $6 \%$ \\
\hline Small and Large intestine & 4 & 1 & 3 & $4 \%$ \\
\hline Kidney & 3 & 1 & 2 & $3 \%$ \\
\hline Undescended testis & 2 & 2 & 0 & $2 \%$ \\
\hline Urinary bladder & 2 & 2 & 0 & $2 \%$ \\
\hline Uterus & 1 & 0 & 1 & $1 \%$ \\
\hline Pancreas & 1 & 1 & 0 & $1 \%$ \\
\hline Miscellaneous & 7 & 5 & 2 & $7 \%$ \\
\hline Total & 100 & 54 & 46 & $100 \%$ \\
\hline
\end{tabular}

In the present study maximum number of aspirate were from Liver 42 cases (42\%) and most of them were malignant. Out of 42 liver aspirate 28 were from male and 14 were from female. similar observation was made by other studies - Zawar MP et al (2007); Sidhalingareddy et al (2011);Sobha Rani G et al (2012); Droese et al (1984) $)^{11} 34 \%$, Porter etal ${ }^{1}(1981)$ 23,8\%, Jan and Mahajan et al (1989) ${ }^{12} 45.5 \%$ also show higher occurrence of liver lesion.second organ with high incidence of involvement in the present study was paraaortic lymph node
12 cases (12\%) followed by ovary(10\%) and Gallbladder(10\%). while in most other studies by Norbrega et al (1994); Adhikari RC et al $(2010)^{13}$; G.I.T was the second common intra-abdominal organ involved.

In the present study population, no complications occurred during and after the procedure. The incidence of needle track seedling was $0.6 \%$ (one of 148 patients of $\mathrm{HCC}$ ) in study done by Reddy et al.

Table 4. Distribution of cases according to FNAC findings

\begin{tabular}{|l|c|c|c|c|c|}
\hline Organ & Inflammatory & Benign & Malignant & Inconclusive & Total \\
\hline 1. Liver & 2 & 2 & 36 & 2 & 42 \\
\hline 2. Lymph node & 2 & & 10 & & 12 \\
\hline 3. Ovary & - & 4 & 6 & & 10 \\
\hline 4. Gallbladder & 2 & - & 7 & 1 & 10 \\
\hline 5. Stomach & - & - & 6 & - & 6 \\
\hline 6. Small \& large gut & 1 & - & 3 & - & 4 \\
\hline 7. Kidney & - & - & 3 & - & 3 \\
\hline 8. Undescended testis & - & - & 2 & - & 2 \\
\hline 9. Urinary bladder & - & - & 2 & - & 2 \\
\hline 10. Uterus & - & - & 1 & - & 1 \\
\hline
\end{tabular}




\begin{tabular}{|l|c|c|c|c|c|}
\hline 11. Pancreas & - & - & 1 & - & 1 \\
\hline 12. Miscellaneous & 4 & - & 3 & - & 7 \\
\hline Total & 11 & 06 & 80 & 03 & 100 \\
\hline
\end{tabular}

Table 5- Neoplastic and inflammatory masses

\begin{tabular}{|c|c|c|}
\hline Abdominal masses & Number & Percentage \\
\hline 1. Neoplastic & 85 & $85 \%$ \\
\hline a) Benign & 5 & $80 \%$ \\
\hline b) Malignant & 80 & $12 \%$ \\
\hline 2. Inflammatory & 12 & $3 \%$ \\
\hline 3. Inconclusive & 3 & $100 \%$ \\
\hline Total & 100 & $3 \%$ \\
\hline
\end{tabular}

Among the total 100 cases studied by the Fine needle aspiration cytology. Satisfactory smears could be obtained in 97 cases in our series. Out of 97 cases 80 cases were found to have malignant cells in aspiration cytology smear. In $17 \%$ of cases aspiration cytology smear reveals benign or inflammatory nature of lesion. In 3 cases FNAC results were inconclusive. Similar observation with majority of intra-abdominal lesions as malignant was found in studies done on deep seated lesion (Sanjay Kumar Nigam et al (2014) 3 , Sidhaligreddy et al (2011), Aftab a Khan et al (1996), Adhakari et al (2010).

\section{Conclusion}

Percutaneous fine needle aspiration cytology is reliable method of diagnosing the various pathological lesions of abdomen. Its diagnostic accuracy is further increased when performed under Radiological guidance. Of all modalities of guidance at present is the most suitable.

\section{REFERENCES}

1. Porter B, Karp W, Forsberg L. Percutaneous cytodiagnosis of abdominal masses by USG guided FNAB. ActaRadiol1981; 22(6) : 663-68.

2. Juul N, Torp-Pedersen S, Holm HH. Ultrasonically guided fine needle aspiration biopsy of retroperitoneal mass lesions. Br J Radiol. 1984;57:43-6. [PubMed] [Google Scholar]

3. Sanjay Kumar Nigam, UmeshPaliwal, Nitu Nigam. "Role of Fine Needle Aspiration Cytology in the Diagnosis of Intra-Abdominal Lumps". Journal of Evolution of Medical and Dental Sciences 2014; Vol. 3, Issue 09, March 3; Page: 2395-2402, DOI: 10.14260/jemds/2014/2150
4. Dosi S, Gupta G, Kawatra M, Chakrabarti PR, Agrawal P, Jain MR. Role of radiological-assisted cytology in intraabdominal lesions: $A 3$ years experience in a tertiary care center. Int J App Basic Med Res 2016; 6:101-5.

5. Sobha Rani G, Faheem N, Sai Prasad BV, Sudhakar Reddy E. Efficiency of ultrasound guided aspiration cytology in deep seated lesions - a diagnostic evaluation. Int J Med Health Sci 2012;1:1-12.

6. Govind Krishna SR, Ananthakrishanan N., Narasimhan R., Veliath AJ. Accuracy of Fine Needle Aspiration Cytology of Abdominal Masses without Radiological Guidance.Indian J. Pathol.Microbiol. 1993; 36(4): 44252.

7. Zawar MP, Bolde S, Shete SS. Correlative study of fine needle aspiration cytology and histology in intra abdominal lumps. SMJ 2007;4.

8. S. Shamshad Ahmed, KafilAkhtar, S. ShakeelAkhtar et al. Ultrasound guided fine needle aspiration biopsy of abdominal masses. JK Science.2006; 8 (4): 200-204.

9. Sidhalingreddy, Andola SK. Fine Needle Aspiration Cytology of Intra-Abdominal Lesions. Journal of Clinical and Diagnostic Research 2011;5:551-8.

10. Joao Nobrega and Guimaraes dos Santos.Aspirative cytology with fine-needle in the abdomen, retroperitoneum and pelvic cavity: a seven year experience of the Portuguese Institute of Oncology, Centre of Porto. European Journal of Surgical Oncology.1994; 20: 37-42. 
11. Droese M, Altmannsberger M, Kehl A, Lankisch PG, Weiss $\mathrm{R}$, Weber $\mathrm{K}$, et al. Ultrasound-guided percutaneous fine needle aspiration biopsy of abdominal and retroperitoneal masses. Accuracy of cytology in the diagnosis of malignancy, cytologictumor typing and use of antibodies to intermediate filaments in selected cases. ActaCytol. 1984;28:368-84. [PubMed] [Google Scholar]

12. Jan G.M., Mahajan R. Ultrasound guided percutaneous fine needle aspiration biopsy (FNAB) of intraabdominal and retroperitoneal masses. Indian J Gastroenterol. 1989;8:99-100. [PubMed] [Google Scholar]

13. RC Adhikari, A Tuladhar, S Shrestha, SK Sharma: Deep Seated Thoracic \&Abdominal lesions: Usefulness of Ultrasound guided F.N.A.C., a 3 year experience: Nepal Med Coll J 2010. 12(1): 20-25.

14. Aftab Khan A., Jan GM., Wani NA. Fine Needle Aspiration of Intra-abdominal masses for cytodiagnosis. J. Indian Med Assoc1996; 94(5):167-69.

How to cite this article : Mishra R,Batham P,Nayak R. Role of Ultrasound Guided Fine Needle Aspiration Cytology in Intra-abdominal lesion. Perspectives in Medical Research 2020; 8 (2):83-87. DOI : 10.47799/pimr.0802.18

Sources of Support: Nil, Conflict of interest: None declared 